\title{
Medical Oncology Education in Egypt Over the Past 50 Years: the Experience of the National Cancer Institute of Cairo University
}

\author{
Hussein M. Khaled ${ }^{1} \cdot$ Amr S. Soliman ${ }^{2}$ \\ Accepted: 24 May 2021 / Published online: 10 June 2021 \\ (c) American Association for Cancer Education 2021
}

\begin{abstract}
This manuscript outlines the progress of education in the field of medical oncology in Egypt over the past 50 years. The manuscript illustrates the origin of the Egyptian medical oncology program since the creation of the only specialized cancer center in the country, the National Cancer Institute of Cairo University (NCI-Cairo) in 1969, from Cairo University Medical School. The manuscript also outlines the NCI-Cairo's educational program for developing a cadre of academic medical oncologists for NCI-Cairo, other Egyptian medical institutions, and countries in the Middle East and Africa. We also emphasize the capacity building that resulted over the past 50 years from academic and professional standpoints, the changing curriculum in medical oncology, and the differences between the medical oncology and clinical oncology education programs in the country. Medical oncology research resulted from international collaborations and highlighted needs for cancer prevention and control. Finally, we propose possible future directions for medical oncology education and research in the country and a roadmap for low- and middle-income countries (LMICs) that are developing their medical oncology programs.
\end{abstract}

Keywords Medical oncology $\cdot$ Professional education $\cdot$ Curriculum $\cdot$ Egypt $\cdot$ LMICs

\section{The History of Oncology in Egypt}

The earliest written description of cancer was found in the Edwin Smith Papyrus dating back to the Sixteenth and Seventeenth Dynasties of the second intermediate period of ancient Egypt (Fig. 1). The papyrus authorship is debated but it might be Imhotep (Fig. 2) who was an architect, high priest, and a physician of the old kingdom (3000-2500 BC). For example, bulging tumors of the breast were a grave disease, and the ancient Egyptians tried to treat tumors with cautery, knives (Fig. 3), and salts. Ancient Egyptians also used arsenic paste that remained in use as the "Egyptian ointment" until the nineteenth century. Recently, the world's oldest known cases of breast cancer were discovered in CT scans of two mummies found in the pharaonic necropolis of Qubbet el-Hawa in Aswan, Egypt.

Hussein M. Khaled

Khussein528@gmail.com

1 Medical Oncology Department, National Cancer Institute, Cairo University, Fom El Khalig Square, Cairo 11796, Egypt

2 City University of New York Medical School, New York, NY, USA
Efforts in creating the field of oncology in recent history in Egypt are credited to the visionary late professors of surgery, Ahmed Lotfy Abo El Nasr and Ismael El Sebaie, and the late professor of radiation oncology, Mahmoud Mahfouz. Discussions about establishing a separate cancer center for oncology practice at Cairo University Medical School started by the 3 professors and others in 1950s, and oncology was recognized as an academic and clinical discipline at Cairo University in 1959. In 1969, the National Cancer Institute of Cairo University (NCI-Cairo) started as an independent academic, clinical, and research school of Cairo University with a primary focus on surgical oncology and a 270-bed hospital (Fig. 4). With professor El Sebaie's specialization in surgical oncology and as the first dean of NCI-Cairo, he introduced radical surgery for cancer and research, primarily on bladder cancer as the most common cancer in Egypt at that time. He also trained the first generation of junior surgeons to specialize in surgical oncology. Radium needles were introduced by professor Mahfouz in 1949; cobalt machines were used at Cairo University Medical School in 1955, the first simulator in 1957; and in 1970, nuclear medicine was introduced to both Cairo University Medical School and NCI-Cairo. 
Fig. 1 Edwin Smith papyrus

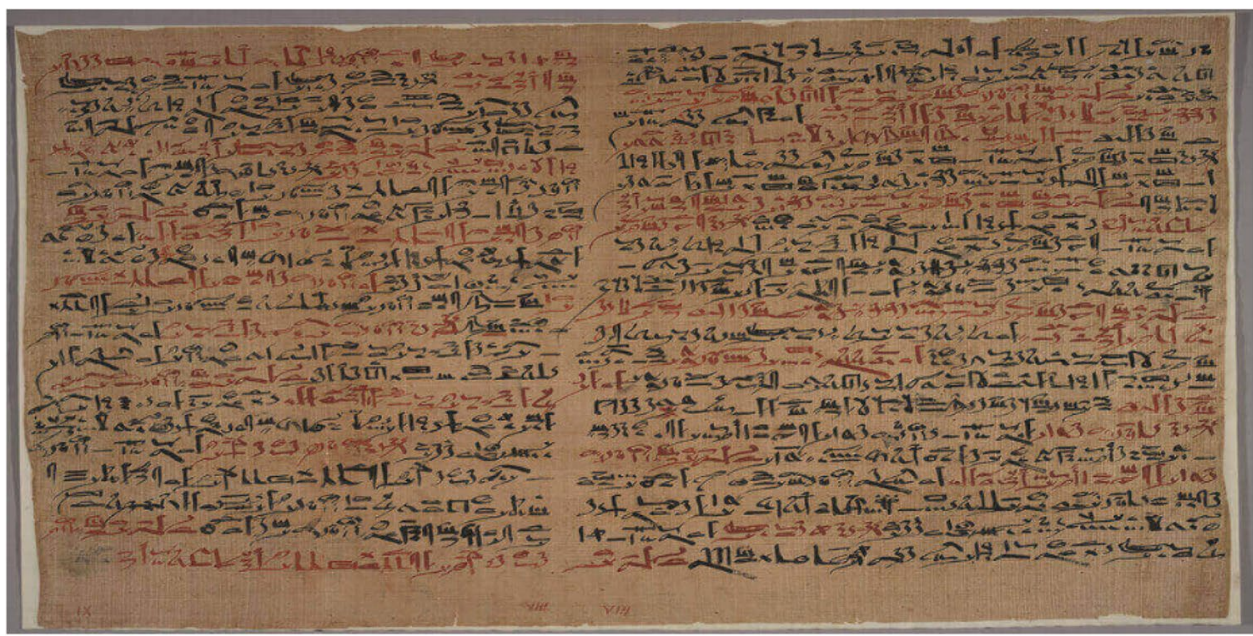

Image credit: U.S. National Library of Medicine

While surgical and radiation oncology and pathology started with the creation of NCI-Cairo in 1969, the medical

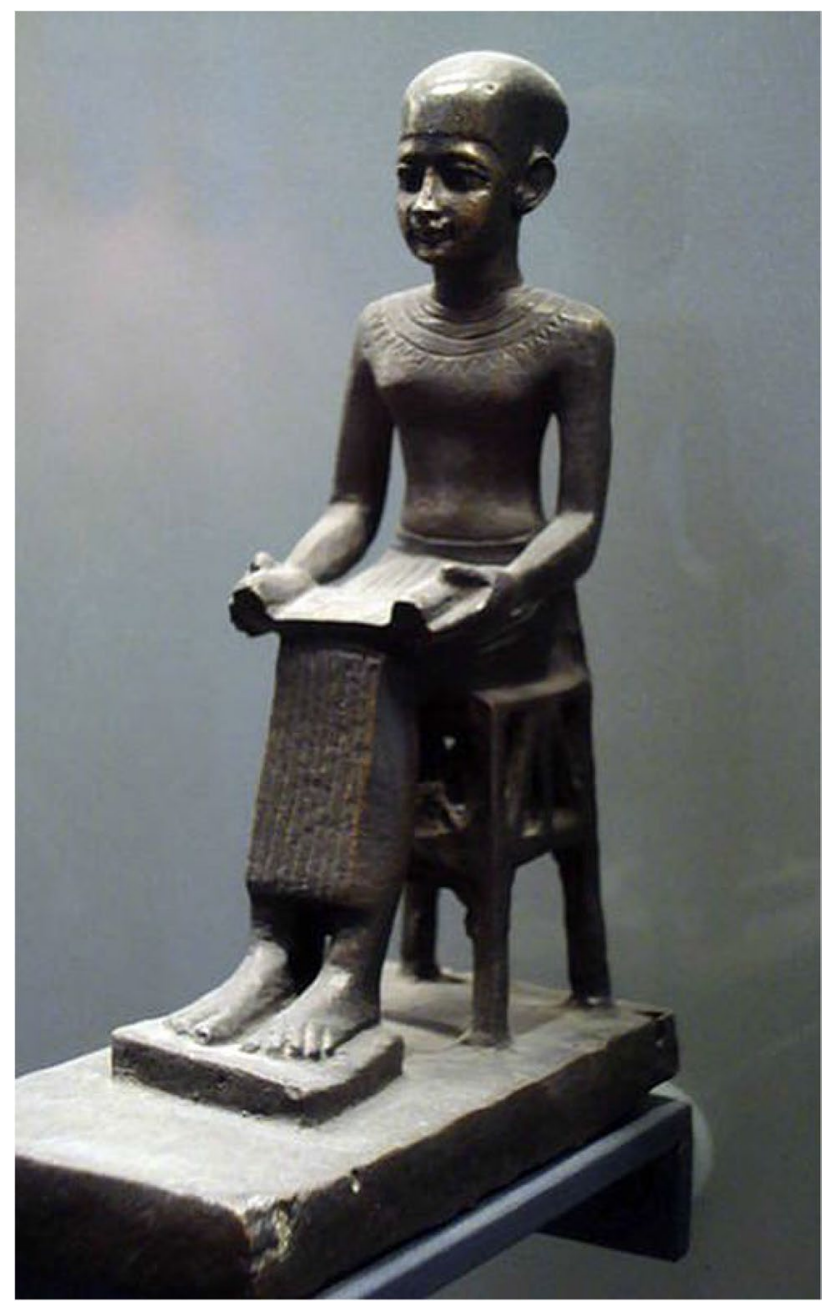

Fig. 2 Imhotep oncology, clinical pathology, and tumor biology departments were created in early 1970s. Before the introduction of medical oncology, systemic cancer therapy was given to patients by surgical oncologists. At that time, four drugs (vincristine, cyclophosphamide, methotrexate, and melphalan) were the only available medications for treatment and were given mostly as single agents. The inpatient service of the medical oncology department started by 30 beds, five of which were assigned for pediatric patients. Two daily outpatient clinics, one for adults and another for pediatric patients, provided diagnosis, follow-up, and administering chemotherapy. At that time, the medical oncology faculty consisted of a junior assistant lecturer, then late professor Reda Hamza, and two residents, one for adults and another for pediatric patients. Professor Hamza had a 6-month training at the Institute Gustave Roussy in Paris. Then the late professor Nazli Gad El Mawla joined the department after she received a short training in medical oncology in the USA and became the first head of the Medical Oncology Department. Owing to the efforts of professors Gad El Mawla and Hamza, the field of medical oncology in Egypt was launched, and the first department in the country was founded.

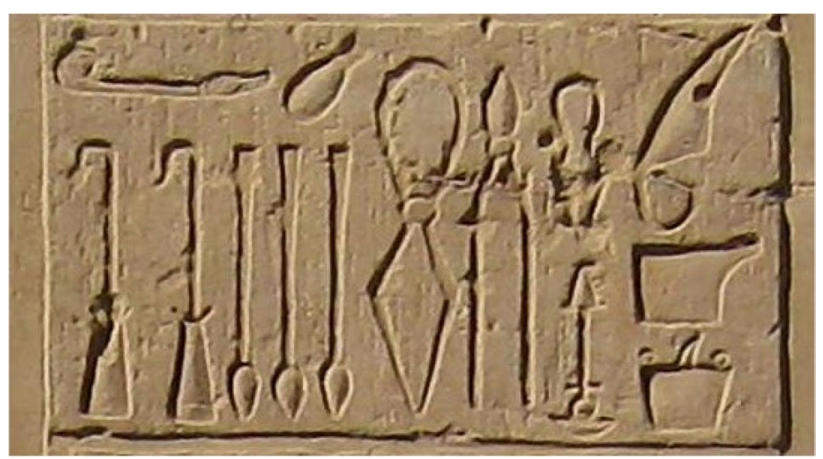

Fig. 3 Ancient Egyptian surgical tools 


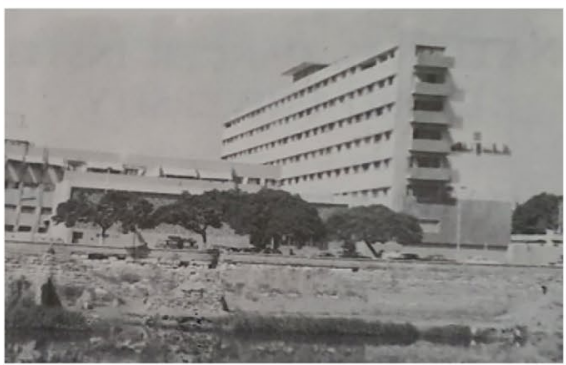

Past (1970)

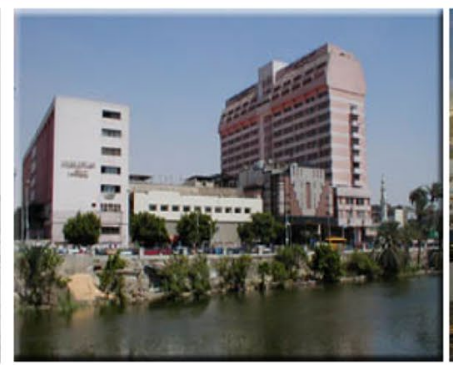

Current

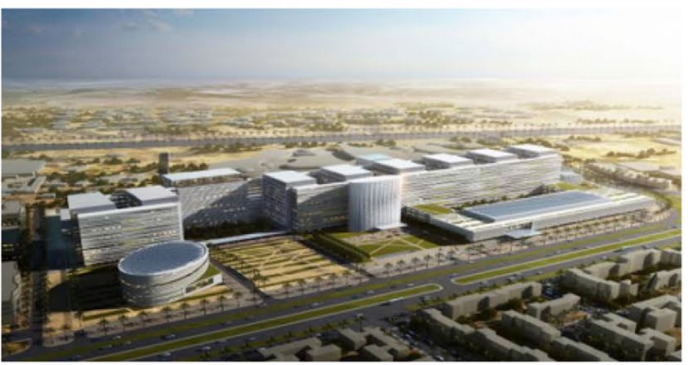

Future Plan

Fig. 4 National Cancer Institute, Cairo University

Multidisciplinary collaboration between the NCI-Cairo departments was emphasized, practiced, and applied to clinical protocols, inpatient and outpatient activities, and followup of patients. According to the hospital-based registry of the NCI-Cairo for the period 1970-1984, 30,416 new cancer cases were managed. Thirty percent of those patients had schistosoma-associated bladder cancer [1]. Currently, the hospital receives a little over 10,000 new patients per year, and the most common cancers are breast cancer among females and liver cancer among males.

\section{Medical Oncology Education at $\mathrm{NCl}-$ Cairo}

With the development of the Department of Medical Oncology and appointment of the first group of residents, NCICairo was not a degree-granting institution and the residents, who followed the British system for education, had to earn masters and doctoral degrees in internal medicine together with post-doctoral medical oncology fellowship. The internal medicine was offered at that time by the Department of Internal Medicine of Cairo University Medical School. After 1986 and until 2006, medical oncology fellows had to earn masters' degrees in internal medicine and elective internal medicine rotations, as part of the doctoral degrees in medical oncology. Post 2006, the system was modified towards more specialization in medical oncology as the candidates had to earn masters' degrees in medical oncology, including required internal medicine rotations followed by doctoral degrees in medical oncology. The curriculum of the master degree spanned over 2 years and included didactic courses in addition to a thesis. The doctoral program spanned over 5-7 years and included didactic courses followed by a dissertation.

Over the past 50 years, the Department of Medical Oncology at NCI-Cairo offered doctoral degrees starting with a few candidates of both internal and external faculty who established new departments of oncology in different academic centers of universities in Egypt and other countries in the Middle East, including Sudan, Libya, Yemen, and Iraq. Also, the department offered degrees to other medical oncologists from non-academic institutions in Egypt who also established new departments and specializations in the field in the Ministry of Health, non-governmental organizations' (NGO) oncology centers, and other medical institutions. As a result of the NCI-Cairo's educational programs, more than 500 medical oncologists are practicing the profession in an academic cancer center of universities belonging to the Ministry of Higher Education, non-academic cancer centers belonging to the Ministry of Health, and numerous oncology services provided by NGO charity hospitals.

In addition to academic education for earning the required degrees for tenure and promotion, the junior faculty in the Department of Medical Oncology of NCI-Cairo has had long-term and short-term training in the USA at the National Cancer Institute in Bethesda, MD Anderson Cancer Center, Memorial Sloan Kettering Cancer Center, and in Europe at the Institute Gustave Roussy in France, Guy's Hospital in London, the Cancer Institute of Netherlands, and the EORTC headquarters. The foreign training has helped in building collaborative relationships and joint research in many fields especially management of bladder cancer, lymphomas, and head and neck and breast cancers.

The settings for educational activities have included (a) outpatient clinics and inpatient wards for solid tumors, hematological malignancies, and breast cancer offering the most appropriate standard of care in the management cancer patients; (b) weekly departmental meetings with journal clubs, mortality and morbidity case presentations in tumor boards; and (c) weekly NCI-Cairo multidisciplinary scientific conferences that are held every Monday morning. Examples of important outcomes of such activities include the development of clinical practice guidelines that are suited for Egyptian patients [2], and research projects that 
have been conducted on the national, regional, and international levels [3-8].

\section{National Collaboration and Sister Institutions}

It was imperative to develop new departments of oncology at the new universities established in different parts of the country over the past 40 years. The distribution of departments and the number of faculty matched the types of cancer specific to the geographic region of the country and the number of cancer patients there. For example, bladder and liver cancers are more concentrated in the northern part of the country. Currently, there are 26 public universities in the country, all of which have medical oncology departments. While some of those departments function as departments of medical oncology, others serve as departments of clinical oncology, offering both chemotherapy and radiotherapy. Currently, those universities are degree-granting institutions and their new generations of faculty earn their degrees locally. Also, beginning 1986, the Ministry of Health established 7 new non-academic oncology centers in different provinces in Egypt and those centers have been staffed by NCI-faculty.

Furthermore, in 2018, the Ministry of Health inaugurated the first women's cancer center for patients covered by the national insurance plan. The center focuses on managing breast and gynecologic malignancies. It is important to note that non-academic professional degrees in medical oncology, namely the Fellowship Program in medical oncology, has been offered by the Ministry of Health and taught by faculty of NCI-Cairo since 1996. This idea of this program is to provide hands-on experience and education needed to non-academic practicing oncologists who work in hospitals of the Ministry of Health. The fellowship includes two parts, the first comprises a 2-year internal medicine training as a general internal medicine training. The second part that spans over 3 years is focused on basics and clinical aspects of medical oncology and is delivered at different academic oncology centers.

Updating the medical oncology practice at NCI-Cairo responded also to patient needs and continuous feedback from patients. For example, the International Union against Cancer (UICC), supported by one of the major pharmaceutical companies, initiated in 2004 a campaign to improve childhood cancer care in developing countries through grants for local research projects [9]. The survey results and the increase in political support for cancer led to more emphasis on professional oncology education, improved access to care and pain management, and psychosocial/educational support for patients. Also, the medical oncology faculty of NCI-Cairo was instrumental in professional education of non-academic physicians by introducing a 2-3-week repeated courses on different aspects of oncology. The courses emphasized aspects that are rarely addressed in general hospitals, such as multidisciplinary oncology policies and clinics, followup oncology clinics for long-term cancer survivors, and early detection clinics. Rehabilitation was also presented to demonstrate disfigurement and dysfunction and their prevention, early detection, and management. Principles of cancer registration, cancer epidemiology, and surgical pathology such as biopsy, frozen section techniques, and cytology were practically demonstrated during these courses. Demonstrations in imaging methods and certain laboratory techniques were carried out. Participating physicians from general hospitals in these courses were also allowed to attend certain operative procedures and/or watch films of such surgical techniques. The same applied to radiotherapy indications and modalities and various chemotherapeutic agents, methods of application, and hormone and immunotherapy.

\section{International Collaboration}

The international collaboration between NCI-Cairo and western institutions started in the 1960s with junior faculty trained at the Institute Gustave Roussy in Paris. Collaboration mainly in radiotherapy application was also part of another agreement with the National Cancer Institute of the Netherlands. The campus then shifted to USA where the NCI-Cairo became a member of the Southwestern Oncology Group (SWOG) in early 1970s. Also, the NCIBethesda was a partner in two major projects for Egyptian faculty development in the fields of bladder cancer and malignant lymphomas. An agreement with the MD Anderson Cancer Center provided the training of several radio-imaging faculty. The gear was shifted again to Europe where the NCI-Cairo became a full member of the EORTC group since 1998.

Also, the Medical Oncology Department is a local organizer of an external session of the European Society of Medical Oncology (ESMO) examination for the past 10 years. This local examination session in Egypt is held at the same day and time as the main session held at the ESMO Congress in Vienna.

Finally, the Medical Oncology Department, led by one of the co-authors (HMK), collaborated with the American Association for Cancer Education (AACE) during the 2000s to update the medical education curriculum of NCI-Cairo and to develop programs for professional cancer education. 


\section{Medical Oncology Research and Education}

Basic science and clinical research related to medical oncology have been a fundamental activity at NCI-Cairo. A substantial part of this research has been devoted to the more common oncological problems, particularly those of national significance, such as bladder cancer related to schistosomiasis, breast and liver cancers, and lymphoma. But until reliable local population-based registries become available again in Egypt [10, 11], there are timely research opportunities that can be explored from hospital registries. These opportunities may empower medical and clinical oncologists in Egypt in decision-making, help prioritize local and national cancer management plans, and tailor therapy for better survival of cancer patients. It should be noted that hospital registries and medical records of cancer patients in Egypt still need investments to facilitate their use in clinical research. Among the limitations that need investments to improve the quality of records are the current reliance on paper records with limited electronic information, lack of linkage of data between departments where patients receive diagnosis and treatment, use of Arabic language in medical records for documenting medications and dosage given by nurses, limited information on patient survival and follow-up, if patients stop coming to the hospital, and lack of linkage of treatment data with the well-established local and national systems of electronic demographic, health, and mortality databases.

Nonetheless, there are important topics that deserve using the existing incomplete and inconsistent data of hospital registries to answer timely medical oncology research questions and to help use the data for education and training. Among those topics are the direct and indirect cost-benefit and cost-effectiveness of the usual and emerging chemotherapeutic agents. Results from such studies using existing data can help streamline and rationalize treatment of individuals and cohorts of patients, inform policy-makers for decision-making regarding financial support of medications, and open the door for new ideas for education into novel therapeutics and management of patients. Another topic for medical oncology research includes the possible differential survival of patients based on the type and dose of treatment, quality of care, and patient demographic and epidemiologic characteristics. Supplementing the treatment data with routine inventory of patient history databases [12] can be an invaluable resource for risk assessment and optimizing treatment of different groups of patients. The patient history database can also serve as a rich resource for patient, professional, and public education.

Another important field that may emerge from using hospital registries relates to patient adherence to prescribed treatment. While cancer centers became readily available and well-staffed with oncologists in Egypt, many patients from remote areas still come NCI-Cairo for initial or second opinions for diagnosis and treatment because of the well-recognized reputation of the institution. Approximately, $45 \%$ of cancer patients seen at NCICairo are from Cairo metropolitan area, while the rest of patients are from other parts of the country $[8,9]$. Considering the significant illiteracy rate of the population and consequently patients in Egypt ( 20\%) [13], and the lack of information about completeness of treatment, it would be interesting to consider new methods for reaching out to patients and their families through telemedicine, patient navigators, and local cancer support groups. Introducing such new tools and approaches will definitely require innovative ways for patient, public, and professional education and research into evaluation of effectiveness of the new interventions and patient acceptability of the interventions. It should be noted that high-speed internet and android phone coverage in Egypt are among the top in the Middle East [14] and that can definitely facilitate new methods for reaching out to patients.

While oncology in Egypt is considered a specialized post-graduate field in medical education, there are many opportunities for increasing interest of medical students in the field and attracting early career medical professionals to choose this specialty and its research in career planning. As is the case in the USA [15], allocating research training funds for summer field experience, skill development programs, and well-designed and validated electives may have significant impact on capacity building for medical oncology and increasing clinical care and research outcomes of medical oncologists and other oncology practitioners.

Finally, while Egypt has been a magnet for medical oncologists from Africa and the Middle East who seek professional and academic degrees in oncology, it would be important to develop special curricula for those trainees and post-graduate students. Such curricula should consider the local cancer profile of the trainees' home countries, resources for cancer management in the foreign countries, and the short-term and long-term plans for setting up new cancer treatment and prevention programs in the trainees' home countries. Furthermore, the Egyptian experience in dealing with incomplete and inconsistent data $[16,17]$ and the introduction of innovative methods for patient, public, and professional education can help those trainees and their countries in developing their own programs. The future training program can also represent a model for other international collaborations and dissemination of successful cancer education programs. 


\section{Future Opportunities}

The profile of cancer in Egypt has changed significantly over the past 50 years. While squamous cell carcinoma of the bladder cancer related to schistosoma infection was the most common cancer among men in Egypt in the 1950s to the early 1980s, this histopathologic type has declined significantly because of the control of this parasitic infestation $[18,19]$. Other cancers that were uncommon until 2000 became the most common cancer in men, such as liver cancer because of the high rate of infection of hepatitis $\mathrm{C}$ virus (HCV) [10,11]. Breast cancer has remained the most common cancer among women in Egypt over the past 50 years. Other cancers that are considered among the top cancers in Egypt include lymphoma, transitional cell carcinoma of the bladder, and head and neck cancer [10,11].

Most of the reliable data on cancer in Egypt resulted from the well-characterized population-based registry in Gharbiah [10] and what is referred to as the National Cancer Registry that included a few provinces in the country [11]. The population-based registries characterized the overtime changes in incidence, staging, and geographic and regional variation of cancer. The research studies that built upon the registries also identified important insights related to clinical and histopathologic profiling of cancer, data completeness [20], barriers to seeking care, factors related to advanced stage at diagnosis, and limited education of primary care physicians and other physicians who are not specialized in oncology and their role in delaying referrals to appropriate cancer care facilities [21]. Unfortunately, the two registries stopped their activities in the past 5 years due to shortage of local and international funding. Other sources of information about cancer in the country have come from hospital-based registries, clinical trials, and masters' and doctoral research and dissertations. However, there have been no quality control or validations of most of the hospital-based data.

There are urgent needs for having reliable data in Egypt for improving medical oncology education and research in Egypt. The reliable data are urgently needed because of the changing pattern of cancer, increasing cancer incidence because of aging of the population and possible change in risk factors, including increasing westernization lifestyles [22] and poverty rates, community development, and cancer awareness; and increasing number of advanced diagnostic and treatment facilities for cancer in the country [23]. All those factors influence stage at presentation and reflect on early detection, diagnosis, treatment, and follow-up of cancer survivors. Therefore, reliable data from hospital-based and population-based cancer registries will be essential. The reliable data should also be a cornerstone for developing oncology curricula in medical schools, graduate, and professional education; training of oncologists; and building outreach oncology and prevention programs. The reliable validated data should also provide insights into delivery of oncologic services in remote and underserved communities, adherence and completeness of cancer treatment, methods for optimizing complete treatment, and remote diagnosis, management, and follow-up of receipt of care. The data could also translate into new fields in medical oncology education such as education for specialization in quality of care, cancer survivorship, and tailored therapy based on genetic profiling of patients. Finally, in these days of the COVID pandemic, remote communication and education have been blooming. The role of telemedicine and tele-education has now been recognized as a productive and an efficient way for building and strengthening more international collaboration.

\section{Summary and Conclusions}

This manuscript illustrated the Egyptian experience in developing and maintaining an educational program for academic and professional medical oncology. The manuscript also defined the changing curriculum, the differences between medical oncology and clinical oncology education, and the research program that resulted from the educational program. It is important to note that the educational experience over the past 50 years utilized significant rich resources for education and training in the country. First, trainees and post-graduate students have had access to a very large number of patients and wide range of presentations of different cancer sites that gave them the knowledge and skills for learning. Second, the trainees had regular and close mentorship by senior faculty, frequent visits by foreign experts from Europe and the USA, and involvement in clinical trials arranged for by the EORTC and other agencies.

However, there have been also challenges that limited the effectiveness of the education and training programs. First, the program has had a significant component of didactic teaching and courses that limited independent self-learning and creative problem-solving. The dose of memorization has been intense and the education was more focused on general medical oncology without motivation or tracks for early specialization or focal areas in medical oncology. Another limitation has been the non-standardized method of doctoral examinations. It is important to note that the Egyptian program followed the British system of education in medical oncology for masters and doctoral education rather than the system of the USA where medical oncology fellowships follow, directly or indirectly, the residency in internal medicine. In spite of the above-listed challenges, it is important to note that trials for improvement have been implemented over the years. For example, the curriculum has been modified 
significantly and included credit-hour educational system and more space for multiple choice questions (MCQ) and objective structured clinical examinations. More participation in local best of ASCO, ASH, and other international conferences gave more exposure to practitioners and educational opportunities for updated learning resources. Finally, to overcome and resolve the limitations and optimize the program in the next decades, the following is recommended. First, the education and training needs should put more emphasis on independent, self-learning, with less courses and more focal areas of molecular and genetic therapeutics, tailored therapy, pharmaco-genetics, and more specializations to emerge, as needed, over the next decades. Also, it is important to consider the conversion of clinical oncology academic degrees and departments into separate entities of radiation oncology, medical oncology, pediatric oncology, and hemato-oncology. Future medical oncology research and theses and dissertation of graduate students need to address the following: (a) rely more on the local cancer profiles, literature, and needs; (b) utilize electronic databases of patient demographic and epidemiologic risk factors, treatment, and survival data; (c) identify and address current and future local research questions; (d) develop local clinical and prevention trials based on local needs and utilize the results for education; and (e) expand education, research, and services into community-centered programs.

\section{References}

1. El-Sebaei I (1971) Cancer in Egypt. Cairo University Press

2. Omar S, El-Badawy S. Khaled HM (2001) Treatment guidelines of the National Cancer Institute of Cairo University. Cairo University Press

3. Soliman AS, Bondy ML, Levin B, Hamza MR, Ismail K, Ismail S, Hammam HM, El- Hattab OH, Kamal SM, Soliman AG, Dorgham LA, McPherson RS, Beasley RP (1997) Colorectal cancer in Egyptian patients under 40 years of age. Int J Cancer 71(1):26-30

4. Lo AC, Soliman AS, Khaled HM, Aboelyazid A, Greenson JK (2010) Lifestyle, occupational, and reproductive factors and risk of colorectal cancer. Dis Colon Rectum 53(5):830-837

5. Soliman AS, Schairer C (2012) Considerations in setting up and conducting epidemiologic studies of cancer in middle- and low-income countries: the experience of a case-control study of inflammatory breast cancer in North Africa in the past 10 years. Cancer Med 1(3):338-349

6. Schairer C, Soliman AS, Omar S, Khaled H, Eissa S, Ayed FB, Khalafallah S, Ayoub WB, Kantor ED, Merajver S, Swain SM, Gail M, Brown LM (2013) Assessment of diagnosis of inflammatory breast cancer cases at two cancer centers in Egypt and Tunisia. Cancer Med 2(2):178-184
7. Schairer C, Hablas A, Seif Eldein IA, Gaafar R, Rais H, Mezlini A, Ben Ayed F, Ben Ayoub W, Benider A, Tahri A, Khouchani M, Aboulazm D, Karkouri M, Eissa S, Pfeiffer R, Gadalla SM, Swain SM, Merajver SD, Brown LM, Soliman AS (2019) Clinicopathologic and mammographic characteristics of inflammatory and non-inflammatory breast cancer at six centers in North Africa. Breast Cancer Res Treat 176(2):407-417

8. Schairer C, Hablas A, Seif Eldein IA, Gaafar R, Rais H, Mezlini A, Ben Ayed F, Ben Ayoub W, Benider A, Tahri A, Khouchani M, Aboulazm D, Karkouri M, Eissa S, El Bastawisy, Yehia M, Gadalla SM, Swain SM, Merajver SD, Brown LM, Pfeiffer RM, Soliman AS (2019) Risk factors for inflammatory and non-inflammatory breast cancer in North Africa. Breast Cancer Res Treat 176(2):407-417

9. Ribeiro RC, Eden T, Hartford J, Lemerle J, Magrath I, SanchoGarnier H et al (2007) My child matters program: a UICCSanofi-Aventis partnership to improve pediatric cancer care in developing countries. J Clin Oncol 25(Suppl 18). https://doi. org/10.1200/jco.2007.25.18_suppl.9526

10. Forman D, Bray F, Brewster DH, Gombe Mbawala C, Kohler B, Pineros $\mathrm{M}$ et al (2014) Cancer incidence in five continents. The International Agency for Research on Cancer (IARC) scientific publication No. 164, Lyon, pp 128-129

11. Ibrahim AS, Khaled HM, Mikhail NM, Baraka H, Mahmoud HK (2014) Cancer incidence in Egypt: results of the national population-base cancer registry program. J Cancer Epidemiol 2014:437971

12. Wu X, Hildebrandt MAT, Ye Y, Chow W-H, Gu J, Cunningham S et al (2016) Cohort profile: the MD Anderson Cancer Patients and Survivors Cohort (MDA-CPSC). Int J Epidemiol 45(3):713-713f. https://doi.org/10.1093/ije/dyv317

13. (2019) Egypt in numbers. The Central Agency for Public Mobilization, Egypt. https://www.capmas.gov.eg

14. Egypt app market statistics in 2020 for Android. https://42mat ters.com/egypt-app-market-statistics

15. Korczak JF, Chung DW, Rosemond E, Von Hoff DD, Haspel RL, Waterbor JW et al (2017) The National Cancer Institute R25 cancer education grants program: a workshop report. J Cancer Educ 32:3-10

16. Dey S, Soliman AS, Hablas A, Seifeldin IA, Ismail K, Ramadan M, El-Hamzawy H, Wilson ML, Banerjee M, Boffetta P, Harford J, Merajver SD (2010) Urban-rural differences in breast cancer incidence by hormone receptor status across 6 years in Egypt. Breast Cancer Res Treat 120(1):149-160

17. Nguyen A, Soliman AS, Hablas A, Ramadan M, Seifeldin I (2020) Geographic distribution of inflammatory breast cancer and non-inflammatory breast cancer in Gharbiah. Egypt J Rare Dis Res Treat 5:6-12

18. Felix AS, Soliman AS, Khaled H, Zaghloul MS, Banerjee M, El-Baradie M, El-Kalawy M, Abd-Elsayed AA, Ismail K, Hablas A, Seifeldin IA, Ramadan M, Wilson ML (2008) The changing patterns of bladder cancer in Egypt over the past 26 years. Cancer Causes Control 19(4):421-429

19. Fenwich A (2019) Egypt's schistosomiasis control programme in the 1980s prepared the ground for the global elimination of schistosomiasis by 2030. Trans R Soc Trop Med Hyg 113:1-3. https://doi.org/10.1093/trstmh/try095

20. Smith B, Ramadan M, Corley B, Hablas A, Seifeldein IA, Soliman AS (2015) Impact of Methodological techniques on improving data collection in the Gharbiah population-based 
cancer registry in Egypt: implications for other low- and middle-income countries. Cancer Epidemiol 39(6):1010-1014

21. Mousa SM, Seifeldin IA, Hablas A, Elbana ES, Soliman AS (2011) Patterns of seeking medical care among Egyptian breast cancer patients: relationship to late-stage presentation. Breast 20(6):555-561

22. Alshahrani S, Hablas A, Chamberlain RM, Meza J, Seifeldin I, Ramadan M, Soliman AS. Changing incidence of uterine cancer in rural Egypt: possible impact of nutritional and epidemiologic transitions. J Glob Oncol Published online July 31, 2019. https://bluejeans.com/320706781/8407?src=calendarLink
23. Corley B, Ramadan M, Smith B, Seifeldin IA, Hablas A, Soliman AS (2015) Cancer registry data reflect improvement in medical care: example from the Gharbiah population-based cancer registry. Egypt J Reg Manag 42(3):86-91

Publisher's Note Springer Nature remains neutral with regard to jurisdictional claims in published maps and institutional affiliations. 